\title{
Size and Structure of Bismuth Nanoparticles Synthesized in Porous Glass Matrix
}

ISSN: 2576-8840

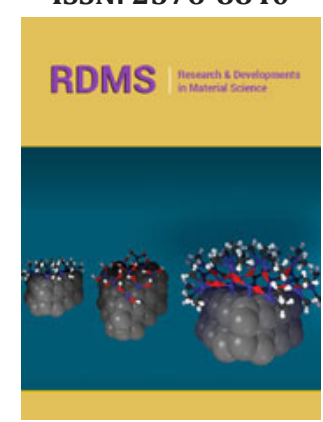

*Corresponding author: Vyacheslav Pak, Herzen State Pedagogical University of Russia, Saint-Petersburg, Moika River Emb., 48, 191186, Russian Federation Email: pakviacheslav@mail.ru

Submission: 囸April 23, 2019

Published: 侮 May 07, 2019

Volume 10 - Issue 5

How to cite this article: V. Pak, O. Golov, V. Stozharov, Yu. Gavronskaya. Size and Structure of Bismuth Nanoparticles Synthesized in Porous Glass Matrix. Res Dev Material Sci. 10(5).RDMS.000745.2019. DOI: 10.31031/RDMS.2019.10.000746

Copyright@Vyacheslav Pak, This article is distributed under the terms of the Creative Commons Attribution 4.0 International License, which permits unrestricted use and redistribution provided that the original author and source are credited.

\author{
Vyacheslav Pak*, Oleg Golov, Valery Stozharov and Yulia Gavronskaya
}

Herzen State Pedagogical University of Russia, Russian Federation, Russia

\section{Opinion}

The use of through canals of porous glass as a re-action chamber ensures the existence of an upper bound on the size of bismuth particles being synthesized. The powder formed by these particles includes, together with the stable rhombohedral form of bismuth, the nanocrystalites of hexagonal modification. The nanoforms of bismuth obtained by various methods typically possess the stable rhombohedral structure [1-10]. However, the parameters of the crystal structure can deviate from their usual values when nanoparticles are formed in the narrow canals of porous glass (PG). Accordingly, this work considers an approach involving the binding of bismuth oxide as an insoluble precursor in the matrix of a PG, followed by $\mathrm{Bi}_{2} \mathrm{O}_{3}$ reduction by glycerol and removal of bismuth nanoparticles from the pores.

The PG used in this work was obtained following the approach [11] in the form of plates with the typical pore diameter of $9 \mathrm{~nm}$ and pores volume of $0.16 \mathrm{~cm}^{3} / \mathrm{g}$. The bismuth oxide $\mathrm{Bi}_{2} \mathrm{O}_{3}$ in the pore space was produced by saturating the $\mathrm{PG}$ with aqueous solution $(\mathrm{pH}=3.5)$ of $\mathrm{Bi}\left(\mathrm{NO}_{3}\right)_{3}$ followed by removal of water and thermal decomposition of the salt at $400{ }^{\circ} \mathrm{C}$. Stepby-step repeating of this procedure with the use of 1.0 mole/l solution led to the oxide content in $\mathrm{PG}$ at $\sim 1.2 \mathrm{mmole} / \mathrm{g}$.

On immersion of washed and dried samples of $\mathrm{Bi}_{2} \mathrm{O}_{3} / \mathrm{PG}$ in glycerol and gradual heating to around $200{ }^{\circ} \mathrm{C}$, a rapid transition of the yellow color of plates to dark grey was observed, indicating the reduction of oxide to the metal form. Characteristically, the subsequent reduction process was accompanied by the gradual PG membranes discoloration (up to total loss of color) which suggests the possibility of the spontaneous escape of metallic bismuth particles into the liquid phase. Meanwhile, the preservation of transparency of glycerol can be explained by the small size and low concentration of the metallic particles dissolved in it.

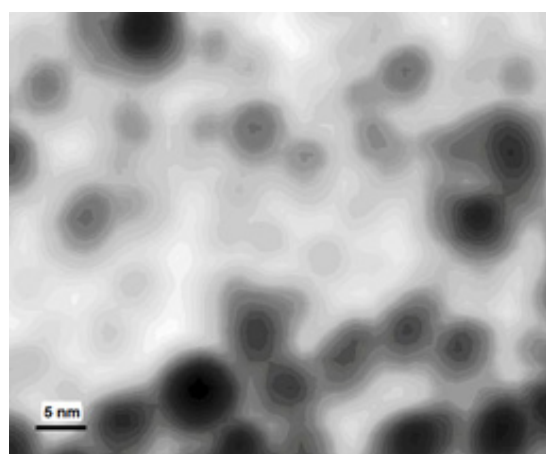

Figure 1: ASM image of primary particles of bismuth.

To determine the shape and size of these particles, the colloid of $\mathrm{Bi} /$ glycerol was placed on the atomically smooth mica surface and kept in vacuum at $180{ }^{\circ} \mathrm{C}$ until the complete evaporation of glycerol. The substrate produced was studied by atomic scanning microscopy (Solver P-47, Italy). A typical ASM image (Figure 1) demonstrates the spherical shape of the bismuth particles and the restriction of their size $(5-8 \mathrm{~nm})$ by the PG pore diameter $(9 \mathrm{~nm})$. The active expulsion of bismuth from the PG-reactor is explained by the high concentration gradient at the phase boundary as well as the con-strained state of solvated metal nanoparticles in the narrow pores of silica. 
Extracting macro-quantities of primary bismuth nanoparticles from glycerol is hindered by their small size, low con-centration, and high viscosity of the medium. Therefore, accumulation of metal in the liquid phase was achieved by increasing the number of plates of $\mathrm{Bi}_{2} \mathrm{O}_{3} / \mathrm{PG}$ used, up to agglomeration of primary particles in visually observable aggregates which were subsequently extracted by a centrifuge. X-ray diffraction pattern (Dron-7, Russia, $\mathrm{CuK}_{\alpha}$ radiation) was obtained from the Bi powder, purified from glycerol by washing in water and ethanol. Beside the representative set of $\mathrm{X}$-ray diffraction lines of the rhombohedral structure, six additional reflexes have been observed (Table 1).

Table 1: Experimental and computed values of inter-plane distances for the hexagonal structure of nanoparticles of bismuth.

\begin{tabular}{|c|c|c|c|c|c|}
\hline No. & $2 \theta$, Grad. & $\begin{array}{c}\text { I, arb. } \\
\text { Units }\end{array}$ & hkl & dexp, $\AA$ & dcalc., $\AA$ \\
\hline 1 & 10.8028 & 320.2 & 100 & 8.1831 & 8.1841 \\
\hline 2 & 12.6193 & 7.4 & 101 & 7.009 & 7.0083 \\
\hline 3 & 21.8171 & 20 & 200 & 4.0704 & 4.092 \\
\hline 4 & 25.4422 & 3.7 & 202 & 3.4981 & 3.5041 \\
\hline 5 & 33.0735 & 3.1 & 5 & 2.7063 & 2.7141 \\
\hline 6 & 59.3465 & 2.6 & 331 & 1.556 & 1.5645 \\
\hline
\end{tabular}

Among those, the dominant high intensity peak at $2 \theta=10.80^{\circ}$ provides for a definitive conclusion of the absence of bismuth oxides, as well as its high-pressure polymorphs. At the same time, it is specifically the small value of the reflex angle which can serve as the basis for considering the possibility of formation of the hexagonal structure of the metal. The criterium for this structure can be written according to [12] as

$$
\sin ^{2} \theta_{h k l}=A\left(h^{2}+h k+k^{2}\right)+C l^{2}
$$

where $A=\lambda^{2} / 3 a^{2} ; C=\lambda^{2} / 4 c^{2} ;$ hkl are Miller indices of corresponding planes; $\lambda\left(\mathrm{CuK}_{\alpha}\right)=1.5406 \AA \dot{A} ; \mathrm{a}$ and $\mathrm{c}$ are lattice constants. Solving equation (1) for appropriate reflexes (Table 1) results in values of parameters $A=8.859 \cdot 10^{-3}, C=3.222 \cdot 10^{-}$ 3 and elementary cell constants $\mathrm{a}=9.450 \AA \mathbf{A}$ and $\mathrm{c}=13.570 \AA \AA$. This identification can be further justified by the closeness of experimental values for inter-plane distances $d_{\text {exp. }}=\lambda / 2 \sin \theta$ (Table
1) to those computed for hexagonal structure by the quadratic expression [12]

$$
1 / d_{\text {calc. }}^{2}=4\left(h^{2}+h k+k^{2}\right) / 3 a^{2}+l^{2} / c^{2}
$$

A noted peculiarity of the observed metallic phase is the ratio $\mathrm{c} / \mathrm{a}=1.436$, which is noticeably smaller than the one characteristic of the ideal hexagonal structure $c / a=1.633$ [12]. This characteristic deviation indicates a reduction in the interlayer distance in primary particles formed in the "constricted" reaction space of PG. Thus, the influence of narrow pores of the PG-reactor manifests itself not only in the limited size of nanoparticles but also in their crystal structure. The share of the hexagonal form of bismuth, determined through the ratio of total reflex-es intensity, is estimated at $\sim 35 \%$.

\section{Acknowledgement}

This work was supported by the Ministry of Education and Science of the Russian Federation in the frame of the basic part of governmental contract.

\section{References}

1. Flores-Castaneda M, Camps E, Camacho-Lopez M, Muhl S, Garcia E, et al. (2015) J Alloys Comp 643: 67.

2. Kim JH, Lee JH (2015) Mater Chem Phys 153: 316.

3. Wang Z, Jiang C, Huang R, Peng H, Tang X (2014) J Phys Chem C 118: 155.

4. Xia F, Xu X, Li X, Zhang L, Zhang LI, et al. (2014) Ind Eng Chem Res 53: 10576.

5. Li B, Nie Z, Gu M, Shao Y, Luo O, et al. (2013) Nanoletters 13: 1330.

6. Velasco-Arias D, Zumeta-Dube I, Diaz D, Santiago-Jasinto P, Ruiz-Ruiz VF, et al. (2012) J Phys Chem C 116: 14717.

7. Brown, Goforth AM (2012) Chem Mater 24: 1599.

8. Derrouiche S, Loebick CZ, Pfefferle L (2010) J Phys Chem C 114: 3431.

9. Yarema M, Kovalenko MV, Hesser G, Talapin D, Heiss WH (2010) J Amer Chem Soc 132: 15158.

10. Boldt R, Kaiser M, Ko'hler D, Krumeich F, Ruck M (2010) Nanoletters 10: 208.

11. Lyubavin M, Burkat T, Pak V (2008) Inorg Mater 44: 203.

12. Warren BE (1990) X-ray diffraction. Dover Publication, New York, USA, P. 21. 